\title{
The theory of planned behaviour and user engagement applied to Facebook advertising
}

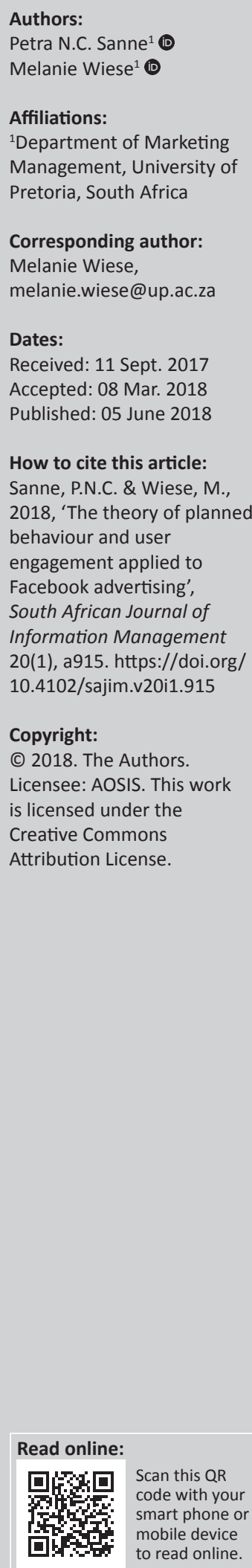

Background: Facebook has become one of the most popular advertising platforms on social media. It is therefore important for social media marketers and researchers to have an understanding of the predictors of Facebook users' engagement with Facebook advertising across all brands and Facebook advertising types.

Objectives: This study aimed to determine whether the theory of planned behaviour could be applied to understand and predict engagement with Facebook advertising.

Method: Non-probability convenience sampling resulted in a sample size of 656 Facebook users above the age of 18 who resided in South Africa. The data collected by means of an online survey were analysed using regression analyses.

Results: The findings indicated that attitude was the strongest predictor of behavioural intention to engage with Facebook advertising, followed by subjective norms. However, perceived behavioural control was found not to be a significant predictor of behavioural intention to engage with Facebook advertising. Furthermore, behavioural intention to engage with Facebook advertising was found to predict actual engagement.

Conclusion: Social media marketers need to focus on influencing attitudes and subjective norms to increase engagement with their Facebook advertisements. Furthermore, the theory of reasoned action was found to be more appropriate to predict engagement with Facebook advertising, as it excludes perceived behavioural control.

\section{Introduction}

Facebook, launched in 2004, was the most popular social media platform in South Africa in 2016, with 13 million users (World Wide Worx 2016), and is a reflection of the continual technology advancements worldwide of social media (Viljoen, Dube \& Muris 2016). Browsing is an activity frequently performed by social network users and equally frequently is the exposure of users to online advertisement (Brajnik \& Gabrielli 2010). Facebook's core offering is connections, which has recently become very popular as a form of marketing - connecting brands and businesses to their target markets (Curran, Graham \& Temple 2011; Maurer \& Wiegmann 2011). Brands interact with their target markets in two broad ways on Facebook: (1) organic (free) and (2) paid advertising (Curran et al. 2011).

Engagement is considered a behavioural response that is prompted by the exposure to an advertisement on Facebook (Mahmoud 2013). Facebook users' engagement with Facebook advertising can be seen as a specific manifestation of consumers' behaviour on Facebook through posts, likes, comments and sharing. As a result, behavioural theories can be applied to understand and predict engagement with Facebook advertising. Thus, this research aims to determine whether the theory of planned behaviour (TPB) can be applied successfully to the context of engagement with Facebook advertising.

Not only could the study benefit researchers to gain a better understanding of the predictors of engagement with Facebook advertising but they can also use the insights to develop more effective strategies to increase engagement. The TPB can then also be considered for application to other social media advertising platforms, such as Instagram and LinkedIn, to explain engagement with advertising on these platforms.

Moreover, for social media marketers who aim to increase engagement with Facebook advertising, the findings of this study can be used to identify what beliefs influence and predict engagement and therefore need to be changed in order to improve engagement with advertising on Facebook. 


\section{Research problem}

As an advertising platform, Facebook provides access to global target markets, and extensive demographic data are available for specific, targeted advertising (Curran et al. 2011). Facebook also offers various insights (e.g. click-through rates and number of views) to social media marketers, making this a popular option for advertisers (Houk \& Thornhill 2013). Overall, Facebook has become one of the most popular advertising platforms on social media (Bannister, Kiefer \& Nellums 2013; Curran et al. 2011).

However, previous research into engagement with Facebook advertising has often had limitations to specific brands, industries or types of Facebook advertisements (Cvijikj \& Michahelles 2013; Luarn, Lin \& Chiu 2015). Furthermore, after optimising a Facebook advertisement for engagement according to suggestions given by previous researchers, unexplained variance in engagement still occurs. Behavioural theories that can be applied to understand and predict engagement with Facebook advertising across all brands, industries and various types of Facebook advertising, which may also explain variances in engagement on posts optimised for engagement, have not been fully explored.

There is thus a limited understanding of the influences on Facebook users' reaction to advertising and engagement with brands on the platform (Bannister et al. 2013; Maurer \& Wiegmann 2011). Brajnik and Gabrielli (2010) argue for more research in the field of Internet and online advertisements because of the impact and momentum of online advertisements, be it on social networks, blogs, websites or news sites. To date, there have been limited studies conducted in South Africa that have attempted to fill this gap. For the most part, Facebook ads are designed to inherently look like a typical post, blurring the lines for the users between paid and unpaid advertising. Furthermore, there is a shortage of research that focus on both paid and organic advertising in a more holistic way. This gap is widened by predictions that social media platforms will continue to push brands deeper into blurred lines between paid advertising and organic content (Renfroe 2015).

\section{Research objective}

The primary objective is to test the validity of the TPB by measuring attitudes towards, social norms of, perceived behavioural control (PBC) of, behavioural intent to and actual engagement with Facebook advertising through an online survey, to determine whether it can be used successfully to understand and predict engagement with Facebook advertising.

\section{Literature review}

\section{Facebook advertising}

In the past decade, social media such as Facebook, Twitter and LinkedIn have radically redefined the communication landscape for both individuals and brands. As a result, social media marketing is becoming increasingly popular (Duffett 2015; Kabadayi \& Price 2014). Social media marketing is thus a form of Internet marketing that utilises social networking platforms as a marketing tool and refers to techniques that target social networks to spread brand awareness or promote products. Facebook in particular has become an increasingly popular social media platform (Jung et al. 2016; Maurer \& Wiegmann 2011). In recent research, Facebook was shown to have over 1.04 billion daily active users (Facebook Investors 2016). Facebook allows brands to interact with the Facebook users in two broad ways. The first is organic (free), which includes brand pages that can be liked and shared, and content posts (including pictures and videos) on brand pages that allow for engagement and interaction between the brand and their target market (Curran et al. 2011; Logan 2014; Luarn et al. 2015). The second is paid advertising, which includes sponsored posts (boosting posts and promoting pages), pay-per-click advertisements, click-to-site advertisements, carousel advertisements, social plugins or applications, and sponsored stories (Curran et al. 2011; Facebook 2011; Gaber \& Wright 2014). Facebook is considered the most popular social media marketing platform, especially for business to customer marketing (Curran et al. 2011; Hubspot 2012, 2013; Maurer \& Wiegmann 2011). Facebook allows brands to set up very targeted advertisements, based on the vast demographic data made available on Facebook by users in order to set up a free account (Bannister et al. 2013; Curran et al. 2011; Maurer \& Wiegmann 2011). Facebook also provides insights into how well campaigns are doing and how well brand pages are performing. These include the click-through rates, the number of times a post or advertisement has been viewed, the number of likes, the number of comments and the number of shares (Curran et al. 2011; Houk \& Thornhill 2013). Facebook brand pages allow a direct interaction with the brand and their target market, and are an ideal way to engage with the target market and discover their sentiments and needs (Bannister et al. 2013; Logan 2014; Maurer \& Wiegmann 2011).

Social networking sites (SNS) such as Facebook have changed the way we communicate, as consumers are not just sharing information about themselves online but they are also voicing their opinions and creating content. This customer empowerment gives social network users the choice to engage with or avoid advertising in this medium.

The term 'engagement' has become a catchphrase that both academics and practitioners have struggled to articulate (Calder, Malthouse \& Schaedel 2009). Some define 'engagement' as how the consumer experiences the platform (Calder et al. 2009) or a cognitive and effective commitment to the active relationship with a brand, as represented by a platform (Rangeley \& Mollen 2012), whereas others see engagement as being a psychological process (Bowden 2009) or behavioural response.

For the purpose of this study, engagement is considered a behavioural response that is prompted by the exposure to an advertisement on Facebook (Mahmoud 2013:298). 
Engagement on Facebook can be measured in various ways. Facebook users can show interest in a Facebook post or a brand page by 'liking' it (Curran et al. 2011; Cvijikj \& Michahelles 2013; Logan 2014). Facebook users can 'share' a post from a page on their own profile 'wall', which will then show up in the newsfeed of the user's connections on Facebook (Cvijikj \& Michahelles 2013; Logan 2014). The Facebook user can comment on a post, which allows them to express their sentiment towards it to others who see the post, as well as the creator of the post (Cvijikj \& Michahelles 2013; Logan 2014). Finally, the Facebook user can click on a paid advertisement, which redirects them to the website or Facebook brand page (Curran et al. 2011; Cvijikj \& Michahelles 2013; Logan 2014). For the purposes of this study, engagement will be defined as a spectrum of behaviour including clicking on, liking, sharing or commenting on a Facebook advertisement or Facebook brand page. Engagement rate is often calculated by adding the number of likes, comments and shares divided by the number of Facebook fans, for example, in a brand community or blog, reflected as a percentage. An engagement rate of $1 \%$ is viewed as good, whereas a rate below $0.5 \%$ likely means that the brand needs to realign their message (Williams 2017).

Although Facebook is considered a popular platform for advertising, there are some concerns around using Facebook for advertising. The invasion of Facebook users' privacy is a major concern, which needs to be kept in consideration when creating marketing strategies for Facebook (Tucker 2014). It should also be considered that users are able to comment on the brand page and posts with their own sentiments. Marketers should consider that this opens a channel for negative word-of-mouth and needs to be carefully monitored to allow quick responses to negative sentiment, to manage brand reputation (Champoux, Durgee \& McGlynn 2012; Maurer \& Wiegmann 2011; Yap \& Lee 2014).

Overall, Facebook offers a unique marketing opportunity for brands to engage with their target markets and create very targeted advertising campaigns (Bannister et al. 2013; Curran et al. 2011; Maurer \& Wiegmann 2011). However, because of a limited understanding of what influences Facebook users' engagement with advertisements and brand pages, marketing strategies are unlikely to be successful (Bannister et al. 2013; Maurer \& Wiegmann 2011). It is thus of interest to apply a behavioural theory, such as the TPB, to consider what predicts the engagement with Facebook advertising in general.

\section{The theory of planned behaviour}

The TPB was developed out of the theory of reasoned action (TRA) (Ajzen 1991), which was originally proposed by Fishbein and Ajzen (1975). The TPB, proposed by Ajzen (1991), adapts the TRA by adding perceived behavioural control (PBC) to allow the model to more accurately explain variations in behaviour that is not entirely voluntary.

An individual develops a positive or negative attitude towards a behaviour based on their behavioural beliefs, perceives subjective norms about the behaviour based on their normative beliefs and gauges PBC based on their control beliefs (Ajzen 1991, 2006). Attitude, subjective norm and PBC influence behavioural intent (BI). Behavioural intent was used as a predictor of actual behaviour, as BI indicates how much effort an individual is willing to put into performing a behaviour, and therefore, the stronger the intention to perform the behaviour, the more likely the behaviour is to be performed (Ajzen 1991, 2006).

Thus, the TPB states that the more positive the attitude towards Facebook advertising, the more peers are perceived to encourage the behaviour (subjective norms), and the greater the individual's perception that they are free to engage or not with the advertising (perceived behavioural control), the stronger the intent to engage with Facebook advertising (behavioural intent), which will in turn predict the actual performance of the behaviour to comment, like or share the advertisement (behaviour).

Since it was developed, the TPB has been used successfully in various contexts to understand and predict human behaviour (Ajzen 1991; Truong 2009). It has been shown to be generalisable to most contexts (Hagger et al. 2007; Ho, Liao \& Rosenthal 2015). Interestingly, depending on the context the TPB was applied to, attitude, subjective norm and PBC had varying influences on $\mathrm{BI}$, with some being stronger influencers than others (Ajzen 1991; Ho et al. 2015).

Previous studies have used the TPB and adaptation of the TPB successfully in newer contexts (Hsu \& Chiu 2004; Leng et al. 2011; Pelling \& White 2009; Truong 2009). The TPB (in various forms) has been used to predict adoption and continued use of online services such as video services, online shopping and e-filing (Crespo \& Del Bosque 2008; Liao, Chen \& Yen 2007; Truong 2009; Wang et al. 2007), as well as predicting the use of social network sites (Baker \& White 2010; Leng et al. 2011), and the continued use of Facebook (Al-Debei, Al-Lozi \& Papazafeiropoulou 2013). The TPB was therefore deemed appropriate for investigating Facebook advertising, as it has been successfully applied to various online and social media contexts previously.

\section{Attitude}

Attitude is an antecedent of behavioural intent in the TPB (Ajzen 1991). Attitude is defined as the degree to which an individual evaluates the behaviour as positive or negative (Ajzen 1991; Mahmoud 2013). Attitude is developed out of behavioural beliefs and subjective outcome evaluations. Behavioural beliefs are the beliefs that performing the behaviour will provide a certain outcome. Subjective outcome evaluations consider the value the individual assigns to the expected outcome (Ajzen 1991).

Attitude can be based on instrumental beliefs and experiential or affective beliefs of performing the behaviour (Ajzen \& Driver 1992). Instrumental beliefs about the behaviour 
consider the use or cost benefits of performing the behaviour. Experiential or affective beliefs about the behaviour consider the emotional benefits of performing the behaviour (Ajzen \& Driver 1991). That is to say, behaviours can be considered important because of their perceived usefulness or because of their perceived enjoyment value (Ho et al. 2015). For the purposes of this study, attitude will be defined as the Facebook users' evaluation (positive or negative) towards engaging with Facebook advertising.

Previous studies in various online contexts have found a strong relationship between attitude and intent. It has been proven that the better the attitude towards a certain behaviour is, the more likely the individual is to form a BI to perform the behaviour (Al-Debei et al. 2013; Baker \& White 2010; Crespo \& Del Bosque 2008:2841; Heirman \& Walrave 2012; Leng et al. 2011; Wang et al. 2007). It can thus be assumed that a positive attitude towards engagement with Facebook advertising will lead to a greater probability of the formation of a behavioural intent to engage with Facebook advertising. It is with this in mind that we hypothesise:

$\mathbf{H}_{1}$ : Attitude towards engaging with Facebook advertising predicts intent to engage with Facebook advertising.

\section{Subjective norms}

Subjective norms are another antecedent of intent in the TPB (Ajzen 1991) and are defined as the social pressures an individual perceives to perform a certain behaviour (Ajzen 1991). These social pressures are often based on how often the individual believes the behaviour occurs among others, and the perception of the individual of the approval or disapproval of the performing of the behaviour by other people (Ajzen 1991; Ho et al. 2015). Subjective norms develop out of normative beliefs and the motivation to comply with these expectations. Normative beliefs are what the individual perceives significant referent individuals to expect in terms of performing the behaviour, and the motivation to comply with these expectations is based on the perceived social pressure and the individual's willingness to comply (Ajzen 1991).

Subjective norms are influenced by both personal referents (such as friends and family) and societal referents (such as mass media) (Ho et al. 2015). Personal referents are generally considered to have a stronger influence on subjective norm than societal referents (Yanovitzky, Stewart \& Lederman 2006). For the purposes of this study, subjective norms will be defined as the social expectations (both on a personal and on a societal level) that the Facebook user perceives regarding engagement with advertising on Facebook.

Previous studies using the TPB have found a positive relationship between subjective norms and BI (Al-Debei et al. 2013; Crespo \& Del Bosque 2008; Heirman \& Walrave 2012; Truong 2009). It has been proven that the more the individual perceives the subjective norms to encourage the performing of the behaviour, the more likely the individual is to form an intent to perform the behaviour (Al-Debei et al. 2013; Crespo \& Del Bosque 2008; Heirman \& Walrave 2012; Potgieter \& Naidoo 2017; Truong 2009). It can thus be assumed that positive subjective norms of engaging with Facebook advertising will lead to a greater probability of the formation of an intent to engage with the advertising.

Subjective norms can be considered specifically important to the study of advertising on Facebook, as Facebook is a collective network based on connections, and 'Friendvertising' (when one Facebook user informs others of what they like by 'liking', 'sharing' or 'commenting' on brand posts or advertisement - paid or organic) greatly influences subjective norm (Logan 2014; Maurer \& Wiegmann 2011). It is also the phenomenon of 'friendvertising' that blurs the boundaries for users between paid and unpaid ads, encouraging users to engage with ads that were not originally intended for them by advertisers. Thus, we hypothesise that:

$\mathbf{H}_{2}$ : Subjective norms of engaging with Facebook advertising predicts intention to engage with Facebook advertising.

\section{Perceived behavioural control}

Perceived behavioural control is the final antecedent of behavioural intent in the TPB (Ajzen 1991). Perceived behavioural control is defined as an individual's perceived ability to perform the behaviour, which varies across situations based on factors that either assist with or obstruct the performing of the behaviour (Ajzen 1991, 2006). Perceived behavioural control is developed based on control beliefs and the perceived power of the influencing factors. Control beliefs are the beliefs the individual has about the extent of control they have over choosing to perform the behaviour, with regard to resources, abilities and barriers (Ajzen 1991). The perceived power of the influencing factor is the individual's perception of how strongly the factor can influence the performing of the behaviour, by either assisting it or obstructing it (Ajzen 1991). For the purposes of this study, PBC is defined as the Facebook users' perceived ability to engage with Facebook advertising.

Perceived behavioural control not only influences behavioural intent but also directly influences behaviour, as the intention to perform the behaviour may be strong, but a factor outside of the individual's control may obstruct the actual performing of the behaviour (Ajzen 1991). However, only the influence on intent will be studied, as studies have shown that PBC does not directly influence behaviour in a social media context (Al-Debei et al. 2013; Baker \& White 2010; Leng et al. 2011).

Previous studies have proven that the greater the PBC towards a certain behaviour is, the more likely the individual is to form a BI to perform the behaviour (Al-Debei et al. 2013; Baker \& White 2010; Heirman \& Walrave 2012; Leng et al. 2011; Truong 2009; Wang et al. 2007). It can thus be assumed that better PBC of engaging with Facebook advertising will 


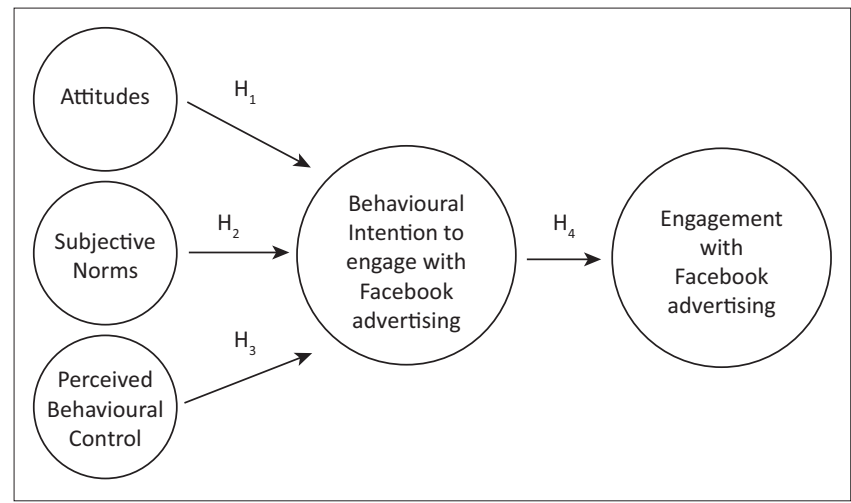

FIGURE 1: The theory of planned behaviour in a Facebook advertising context.

lead to a greater probability of the formation of a behavioural intention to engage. Therefore, we hypothesise that:

$\mathbf{H}_{3}$ : $\mathrm{PBC}$ of engaging with Facebook advertising predicts intention to engage with Facebook advertising.

\section{Behavioural intention and behaviour}

Behavioural intention is considered a direct antecedent to behaviour and is used in the TPB to predict actual behaviour (Ajzen 1991; Ho et al. 2015) and may be defined as the amount of effort an individual is willing to exert in order to perform the behaviour in question (Ajzen 1991). In the context of this study, the behaviour to be measured is Facebook users' engagement with Facebook advertising. Previous studies support the relationship between $\mathrm{BI}$ and behaviour in a social media context (Al-Debei et al. 2013; Baker \& White 2010; Leng et al. 2011). The BI to be measured will thus be Facebook users' intention to engage, and thus, we hypothesise that:

$\mathbf{H}_{4}$ : Intent to engage with Facebook advertising predicts actual engagement with Facebook advertising.

The TPB applied to Facebook advertising as hypothesised above is shown in Figure 1.

\section{Research methodology}

The study population consisted of Facebook users who had been active on Facebook in the month prior to data collection, who were above the age of 18 and who resided in South Africa. Because of the lack of a sampling frame, this study used non-probability, convenience sampling. For the purposes of this study, 656 completed questionnaires were collected. A sample size of above 400 respondents was considered adequate to conduct this study as previous studies testing similar constructs made use of sample sizes between 200 and 400 respondents (Pelling \& White 2009; Truong 2009).

After obtaining ethical clearance, the questionnaire was uploaded to an online survey platform (Qualtrics) and distributed by means of an email to an existing professional database of 10000 people, as well as posted, shared and boosted on Facebook. This method of data collection was considered appropriate as the study population consisted of an online community.
The questionnaire used for this study included three screening questions, ensuring the respondents were active Facebook users, were above the age of 18 and resided in South Africa. Five items measuring demographic information of the respondents and general Facebook usage were also included. Existing scales were used to construct the questionnaire. Cronbach's alpha values for reliability of items were considered, where a value above 0.7 is considered acceptable (Pallant 2010). All included existing scale items had previous Cronbach's alpha values of above 0.74, indicating reliability. Respondents were asked about their beliefs about Facebook advertising across all brands, industries and advertisement (organic and paid) types.

Attitude, subjective norms, $\mathrm{PBC}$, intent and past behaviour (PB) were measured on a 7-point Likert scale where $1=$ strongly disagree and $7=$ strongly agree, considered appropriate because of use in previous studies on the TPB (Ajzen 2006; George 2004; Ho et al. 2015; Truong 2009). Attitude was measured with six items measuring users' attitude towards engaging with Facebook advertising by considering whether they perceive it to be good, wise, favourable, beneficial, positive and pleasant (e.g. I think engaging with Facebook ads is wise). These items measure both instrumental and affective beliefs. These items were reworded to reflect the Facebook context from four previous studies that applied the TPB in an online context (Chang \& Zhu 2011; George 2004; Truong 2009; Wang \& Sun 2010). Subjective norms were measured with four items, reworded to reflect the context of Facebook advertising, adapted from Al-Lozi (2011), Chang and Zhu (2011), George (2004) and Truong (2009), and included items such as 'People who influence my behaviour think I should engage with Facebook ads'. Perceived behavioural control was measured with five items (e.g. engaging with Facebook ads is entirely in my control), reworded to reflect the context of Facebook from Al-Lozi (2011) and Truong (2009). Behavioural intent was measured with two items (e.g. I have the intention to engage with Facebook ads in the next 6 months), reworded to reflect the Facebook advertising context from Al-Lozi (2011) and Truong (2009) for the purpose of this study. Past behaviour was measured with five items, based on the different Facebook engagement behaviours such as 'I have liked Facebook ads in the past' and 'I have commented on Facebook ads in the past' (Curran et al. 2011:28; Cvijikj \& Michahelle 2013; Logan 2014).

A pretest was conducted to reveal issues or errors with the self-administered questionnaire's scale items. By using a convenience sampling method, the pretest was administered to respondents similar to those in the study population. No issues were found in the pretest.

\section{Results \\ Sample profile}

The study was conducted using a sample of 656 respondents, of which $54.5 \%$ were male and $46.5 \%$ were female. The majority of respondents were between the ages of 46 and 
55 years $(33.7 \%), 56-65$ years $(21.6 \%)$ and 36-45 years (20.8\%). The 'younger' Facebook users were in the minority with $9.7 \%$ between the ages of 18 and 25 years and $7.2 \%$ between the ages of 26 and 35 years. This skewness could be because of the convenience sampling employed or reflecting an 'older' generation of Facebook users. Lovett (2011) reported that the fastest-growing group of social media users is people over 50 years and predicted that the number of older SNS users is expected to grow significantly. Lovett's predications are confirmed as Neal (2014) reported that younger Facebook users are leaving Facebook for other social media platforms as a result and contributing to a shift to the typical Facebook user being older. With regard to Facebook, the majority of respondents were active on Facebook daily $(66.4 \%)$ or two to three times a week (20.5\%). Furthermore, the majority of respondents had been Facebook users for more than 5 years $(69.7 \%)$ or had been Facebook users for $3-5$ years $(22 \%)$.

\section{Validity and reliability}

Exploratory factor analysis (EFA) using principle axis factoring was performed on the 22 items used to measure the TPB (attitude, subjective norms, PBC, BI and PB) applied to Facebook advertising, using SPSS version 23. Before performing principle axis factoring, the suitability of the data for performing an EFA was evaluated using the KaiserMeyer-Olkin measure of sampling adequacy and Bartlett's test of sphericity (Pallant 2010). The correlation matrices showed that all the coefficients had values of 0.3 or above. The Kaiser-Meyer-Olkin values were all above the recommended minimum value of 0.5 (Kaiser 1974), and Bartlett's test of sphericity was significant in each analysis. Thus, the factorability of the correlation matrices was supported, and the data were considered suitable for factor analysis (Tabachnick \& Fidell 2007). Table 1 shows the results of the EFAs performed, indicating that each scale extracted one factor, with the cumulative percentage of variance that was explained by the extracted factor. Internal consistency reliability was assessed using Cronbach's alpha, where a value of 0.7 or above is considered acceptable internal consistency reliability (Pallant 2010). The overall mean scores and standard deviations of each scale are also indicated.

Convergent and discriminant validity were assessed with the aid of the EFAs. Each of the 22 items was loaded only once (discriminant validity) on one of the factors extracted, at a value of 0.6 or higher (convergent validity). Thus, the items measuring the identified constructs were considered valid.

\section{Multiple regression analysis}

Before conducting the multiple regression analysis to determine whether attitude, social norm and $\mathrm{PBC}$ predict intention to engage with Facebook advertising, the researcher ensured that all the necessary assumptions were met, including: The sample size required for a multiple regression

TABLE 1: Mean, standard deviations and construct validity and reliabilities.

\begin{tabular}{|c|c|c|c|c|c|c|c|}
\hline Constructs & Factor loadings & Items & $\begin{array}{l}\text { Factors } \\
\text { extracted }\end{array}$ & $\begin{array}{l}\text { Cumulative } \\
\text { percentage } \\
\text { of variance } \\
\text { explained }\end{array}$ & $\begin{array}{l}\text { Cronbach's } \\
\text { alpha }\end{array}$ & Mean & $\begin{array}{l}\text { Standard } \\
\text { deviation }\end{array}$ \\
\hline Attitude: I think engaging with Facebook ads is ... & & 6 & 1 & $84.92 \%$ & 0.971 & 3.05 & 1.596 \\
\hline Positive & 0.949 & - & - & - & - & - & - \\
\hline Favourable & 0.947 & - & - & - & - & - & - \\
\hline Wise & 0.922 & - & - & - & - & - & - \\
\hline Good & 0.919 & - & - & - & - & - & - \\
\hline Beneficial to me & 0.906 & - & - & - & - & - & - \\
\hline Pleasant & 0.885 & - & - & - & - & - & - \\
\hline Social norms: ... engage with Facebook ads & & 4 & 1 & $71.01 \%$ & 0.904 & 2.56 & 1.388 \\
\hline People who are important to me think I should & 0.934 & - & - & - & - & - & - \\
\hline People who influence my behaviour think I should & 0.857 & - & - & - & - & - & - \\
\hline Others I know expect that people like me should & 0.798 & - & - & - & - & - & - \\
\hline People who are important to me & 0.772 & - & - & - & - & - & - \\
\hline Perceived behavioural control & & 5 & 1 & $53.34 \%$ & 0.843 & 5.87 & 1.195 \\
\hline Engaging with Facebook ads is entirely in my control & 0.872 & - & - & - & - & - & - \\
\hline I can choose the Facebook ads I want to engage with & 0.767 & - & - & - & - & - & - \\
\hline I am free to engage with Facebook ads as I want to & 0.686 & - & - & - & - & - & - \\
\hline $\begin{array}{l}\text { I have the knowledge and ability to engage with Facebook } \\
\text { ads }\end{array}$ & 0.668 & - & - & - & - & - & - \\
\hline I have the resources needed to access Facebook ads & 0.633 & - & - & - & - & - & - \\
\hline Behavioural intent & & 2 & 1 & $89.61 \%$ & 0.943 & 2.69 & 1.869 \\
\hline I have the intention to engage with Facebook ads & 0.947 & - & - & - & - & - & - \\
\hline I will engage with Facebook ads & 0.947 & - & - & - & - & - & - \\
\hline Engagement Behaviour: I have... & & 5 & 1 & $66.08 \%$ & 0.906 & 3.21 & 1.851 \\
\hline Liked Facebook ads in the past & 0.890 & - & - & - & - & - & - \\
\hline Clicked on Facebook ads in the past & 0.810 & - & - & - & - & - & - \\
\hline Engaged with Facebook ads in the past & 0.809 & - & - & - & - & - & - \\
\hline Shared Facebook ads in the past & 0.787 & - & - & - & - & - & - \\
\hline Commented on Facebook ads in the past & 0.764 & - & - & - & - & - & - \\
\hline
\end{tabular}


is suggested to be three times the number of independent variables added to 50 (Tabachnick \& Fidell 2007). This study had 656 responses, and thus, this assumption was met. Correlations between each independent variable (IV) and the dependent variable (DV) are recommended to be above 0.3 (Pallant 2010). All variables met this condition and therefore met the assumption, with the exception of PBC, which was found to have a correlation coefficient of only 0.139 with BI. However, because of previous studies having shown that it is a significant predictor of BI within the TPB, it was retained (Al-Debei et al. 2013; Baker \& White 2010; Heirman \& Walrave 2012; Leng et al. 2011; Truong 2009; Wang et al. 2007).

Multicollinearity was checked for by inspecting the correlations table, ensuring that coefficients between IVs were not exceeding 0.9 (Pallant 2010:158). Furthermore, all the IVs had tolerance values above 0.1 and variance inflation factors below 10 (Pallant 2010:158). In order to check for significant outliers, the Mahalanobis distance was calculated, which has a recommended maximum value of 16.27 for multiple regressions with three IVs (Pallant 2010). In the first analysis, eight significant outliers were detected and subsequently deleted. Thereafter, the analysis was run again, and no significant outliers were detected. The Mahalanobis distance calculated in the second analysis was 14.446 (Pallant 2010). The Cook's distance in the second analysis was less than 1, showing that any further potential outliers did not have a great influence (Tabachnick \& Fidell 2007). The normality, linearity and homoscedasticity assumptions were all met as the data points fell in a fairly straight line on the normal P-plot, and the scatterplot of the standard residuals has most of the points concentrated in the middle, and looked roughly rectangular (Pallant 2010; Tabachnick \& Fidell 2007).

The Pearson's product moment correlations that were conducted for the three IVs (attitude, SN and PBC) and the DV (BI) showed significant linear relationships between each of the IVs and the DV $(p<0.05)$. The overall correlation coefficient (R-squared value) for the regression model was 0.649 , indicating that the three IVs (attitude, subjective norms and $\mathrm{PBC}$ ) explain $64.9 \%$ of the variance in behavioural intention. An inspection of the ANOVA test results revealed that the regression model was significant $(p<0.05)$.

Inspection of the coefficients table revealed that attitude and subjective norms were both statistically significant predictors of behavioural intent $(p<0.05)$. However, PBC was not a statistically significant predictor of intent $(p>0.05)$. Thus, a second regression was run, deleting $\mathrm{PBC}$ as an independent variable (IV) to evaluate the contribution of $\mathrm{PBC}$ to the overall model.

The second multiple regression confirmed that PBC did not have a significant contribution to the model, as the overall correlation coefficient (R-squared value, $R^{2}$ ) for the second regression was 0.649 . No change in the $R^{2}$ value implies that PBC had no significant impact on the overall variance explained by the regression model. An inspection of the ANOVA test results revealed that the second regression
TABLE 2: Predictors of behavioural intent to engage with Facebook advertising.

\begin{tabular}{lccc}
\hline Model & Standardised coefficients & $t$ & $p$ \\
\hline (Constant) & - & -3.403 & $0.001^{*}$ \\
Attitude & 0.706 & 23.1 & $0.000^{*}$ \\
Subjective norms & 0.143 & 4.683 & $0.000^{*}$ \\
\hline
\end{tabular}

*, Statistically significant.

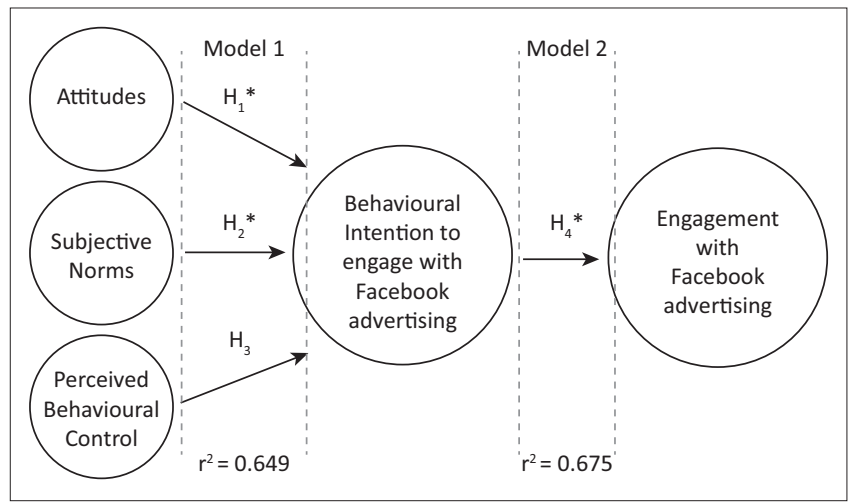

FIGURE 2: Results of theory of planned behaviour applied to Facebook advertising.

model was significant $(p<0.05)$. Thus, PBC was removed from further analyses to ensure a more parsimonious model.

Inspection of the coefficients table in the second regression revealed that both attitude and subjective norms were statistically significant predictors of behavioural intent $(p<0.05)$. As shown in Table 2, attitude made the strongest unique contribution to explaining behaviour intent $(p<0.05$; $\beta=0.706)$. Subjective norms made a small unique contribution to explaining BI $(p<0.05 ; \beta=0.143)$.

\section{Single regression analysis}

A single regression analysis was run with one IV (BI) and the $\mathrm{DV}$ ( $\mathrm{PB}$, i.e. engagement with Facebook advertising) to determine whether intent predicts engagement with Facebook advertising. Similar to the assumptions previously listed, the researcher ensured that all the assumptions were met. The Pearson's product moment correlation that was conducted showed a significant linear relationship between the IV and the DV $(p<0.05)$. The overall correlation coefficient $\left(\mathrm{R}^{2}\right.$ value $)$ for the regression model was 0.675 , indicating that behavioural intent explains $67.5 \%$ of the variance in engagement with Facebook advertising. An inspection of the ANOVA test results revealed that the regression model was significant $(p<0.05)$.

Inspection of the coefficients table revealed that behavioural intent was a statistically significant predictor of engagement with Facebook advertising $(p<0.05)$. Intention made a strong unique contribution to explaining engagement with Facebook advertising $(p<0.05 ; \beta=0.822)$.

Therefore, the following conclusions can be made regarding the hypotheses, as shown in Figure 2:

- $\mathrm{H}_{1}$ that attitude towards engaging with Facebook advertising predicts BI to engage with Facebook advertising was therefore accepted $(\beta=0.706 ; p<0.05)$. 
- $\mathrm{H}_{2}$ that subjective norms of engaging with Facebook advertising predict BI to engage with Facebook advertising was therefore accepted $(\beta=0.143 ; p<0.05)$.

- $\mathrm{H}_{3}$ that $\mathrm{PBC}$ of engaging with Facebook advertising predicts $\mathrm{BI}$ to engage with Facebook advertising was not accepted $(p>0.05)$.

- $\mathrm{H}_{4}$ that BI to engage with Facebook advertising predicts actual engagement with Facebook advertising was accepted $(\beta=0.822 ; p<0.05)$.

\section{Discussion}

The TPB proposes that attitude, subjective norms and PBC predict behavioural intent and thereby predict actual behaviour (Ajzen 1991, 2006). This study accordingly determined whether the TPB could be applied in a Facebook advertising context to predict engagement with Facebook advertising by considering attitude towards, subjective norms of and PBC of engagement with Facebook advertising in a South African context.

Results from this study indicated that the Facebook user's attitude and subjective norms significantly predicted intention to engage with Facebook advertising, which in turn significantly predicted actual engagement with Facebook advertising. This supports previous findings that attitude and subjective norm predict behavioural intent and intent predicts actual behaviour in a social media context (Al-Debei et al. 2013; Baker \& White 2010; Leng et al. 2011) and in an online context (Heirman \& Walrave 2012; Truong 2009). It is also in line with the findings of Viljoen et al. (2016) that Facebook as a platform are able to significantly influence intentions. However, results also indicated that PBC did not significantly predict intent to engage with Facebook advertising nor did it affect the $\mathrm{R}^{2}$ value of the model. This contrasts previous findings that $\mathrm{PBC}$ is a significant predictor of intention in a social media context (Al-Debei et al. 2013; Baker \& White 2010; Leng et al. 2011) and in an online context (Heirman \& Walrave 2012:618; Truong 2009:183). This may be because of the fact that a Facebook user is already capable of using Facebook and thus does not require additional abilities to engage with Facebook advertising. As a result, this finding suggests that the TRA is more suitable to this context than the TPB, as it excludes PBC as a predictor of intention. This finding also suggests that social media marketers can predict Facebook advertising engagement determining attitude towards and subjective norms of engaging, and thus determining intention to engage with Facebook advertising.

Results further indicated that attitude was the strongest significant predictor of intention to engage with Facebook advertising. This finding supports previous findings that attitude is the strongest predictor of BI in a social media and an online context (Baker \& White 2010; Heirman \& Walrave 2012; Leng et al. 2011). It is therefore recommended that social media marketers should focus on changing Facebook users' attitudes towards advertising on Facebook by focusing on influencing users to believe that Facebook advertising is good, wise, favourable, pleasant and a positive thing that is beneficial to the user. The results of Chu (2011) suggest that users' attitude towards the platform at large is a good indicator of their attitude towards its content and is good news for advertisers. Thus, the more interactive and enjoyable features Facebook creates, the more users will develop a positive attitude towards Facebook in general but also towards advertising on Facebook. Users are more likely to accept and rely on the information that matches the social context of the platform and resembles social post. In order to ensure that a positive attitude is maintained towards advertising, it must be delivered in a way that is not overwhelming or intrusive to the users in a space that they consider social, yet intimate and private.

Furthermore, the results also indicated that subjective norms were a significant predictor of intention to engage with Facebook advertising and are in line with previous findings of tests conducted in a social media and in an online context (Al-Debei et al. 2013; Heirman \& Walrave 2012; Potgieter \& Naidoo 2017; Truong 2009). However, it is difficult for social media marketers to directly influence and change subjective norms. It is therefore recommended that social media marketers focus on improving attitudes towards Facebook advertising and optimising Facebook advertisements to increase engagement with this form of advertising, as by increasing engagement with specific Facebook advertisements, social media marketers could influence 'Friendvertising' in order to influence and change subjective norms towards Facebook advertising.

The above discussion on attitude and subjective norms therefore indicates that advertisements with a competitive angle (remunerative) that are entered by either sharing the advertisement or by tagging other Facebook users in the comments (Friendvertising) could be a way of using both attitudes and subjective norms to increase engagement with Facebook advertising. We thus agree with Potgieter and Naidoo (2017) that firms are encouraged to empathise the social needs (subjective norms) of users not only for use of Facebook but also to promote engagement with Facebook advertising. Furthermore, social media marketers should focus on creating Facebook advertisements that are entertaining and interactive by incorporating an entertaining video, image or a quiz in order to change attitudes, increaseengagement and influence 'Friendvertising' (thereby influencing subjective norms).

\section{Summary and conclusion}

Overall, this study demonstrated some support for the application of the TPB model in the context of predicting engagement with Facebook advertising but more so for utilising TRA. This study contributed to the limited research into behavioural theories applied to brands in various industries and in both paid and organic Facebook advertisements. In addition, it also practically aids social media marketers. By combining previous knowledge about encouraging engagement with Facebook advertising and the 
findings presented in this study, advertisers can optimise Facebook advertisements for engagement across brands, industries and types of Facebook advertisements.

Based on this preliminary investigation, future research should continue to investigate Facebook user's engagement with Facebook advertising to further our understanding of this growing communication and advertising platform to aid in the development of appropriate marketing and advertising strategies. Because of the use of a non-probability convenience sampling method, the sample was skewed towards the older age group (between 36 and 65 years old) and although in line with the 'ageing' Facebook population, indicating potential bias of the results. It is therefore recommended that future researchers make use of a quota sampling method to achieve a better sample distribution. Future research should consider finding additional predictors and influencers of intention to engage with Facebook advertising. These may include content type, post media type, and the day and time of posts (Cvijikj \& Michahelles 2013; Luarn et al. 2015), as well as influencers of the intention to engage with Facebook advertising, such as peer influence, privacy concerns and perceived invasiveness of the Facebook advertising (Jung et al. 2016). Finally, future research may also be conducted to consider whether the TRA can be applied to other social media advertising contexts, for example, Instagram advertising, Twitter advertising and LinkedIn advertising.

Although some may argue that investigating users' engagement with paid and unpaid ads together could be a limitation of the study, we view this as our main contribution. The distinction between the two is not as clear as some would like to believe even for marketers and almost impossible for Facebook users. Facebook users are not always aware that the ads they receive are indeed paid ads. The reality is that when brands drive initial engagement via paid or unpaid advertising on Facebook, it will morph into organic impact over the next few posts, reposts and sharing. Thus, causing paid and organic ads to overlap, as advertising is anything that exposes a brand's name into the minds of potential customers. Therefore, it is important for marketers and advertisers alike to follow a more holistic approach to Facebook advertising, instead of a silo or compartmentalised approach where paid and unpaid advertising are treated separately.

\section{Acknowledgements Competing interests}

The authors declare that they have no financial or personal relationships that may have inappropriately influenced them in writing this article.

\section{Authors' contributions}

M.W. conceived the original idea and supervised the project. P.N.C.S. developed the theoretical underpinning, collected the data and performed the statistical analytics. She wrote the manuscript with support from M.W. Both authors contributed to the final manuscript, P.N.C.S. as student and M.W. as the study supervisor.

\section{References}

Ajzen, I., 1991, 'The theory of planned behaviour', Organizational Behaviour and Human Decision Processes 50(2), 179-211. https://doi.org/10.1016/07495978(91)90020-T

Ajzen, I., 2006, 'Constructing a theory of planned behaviour questionnaire', Unpublished manuscript, Based on the appendix in: Fishbein, M. \& Ajzen, I., 2010 Predicting and changing behaviour: The reasoned action approach, pp. 449-457, Psychology Press, New York.

Ajzen, I. \& Driver, B.L., 1991, 'Prediction of leisure participation from behavioural, normative, and control beliefs: An application of the theory of planned behaviour', Leisure Sciences 13(3), 185-204. https://doi.org/10.1080/01490409109513137

Ajzen, I. \& Driver, B.L., 1992, 'Application of the theory of planned behaviour to leisure choice', Journal of Leisure Research 24(3), 207-224. https://doi.org/10.1080/002 22216.1992.11969889

Al-Debei, M.M., Al-Lozi, E. \& Papazafeiropoulou, A., 2013, 'Why people keep coming back to Facebook: Explaining and predicting continuance participation from an extended theory of planned behaviour perspective', Decision Support Systems 55(1), 43-54. https://doi.org/10.1016/j.dss.2012.12.032

Al-Lozi, E., 2011, 'Explaining users' intentions to continue participating in Web 2.0 communities: The case of Facebook in the Hashemite Kingdom of Jordan', Unpublished doctoral thesis, Brunel University, London, viewed October 2016, from http://dspace.brunel.ac.uk/bitstream/2438/6292/1/FulltextThesis.pdf

Baker, R.K. \& White, K.M., 2010, 'Predicting adolescents' use of social networking sites from an extended theory of planned behaviour perspective', Computers in Human Behaviour 26(6), 1591-1597. https://doi.org/10.1016/j.chb.2010.06.006

Bannister, A., Kiefer, J. \& Nellums, J., 2013, 'College students' perceptions of and behaviours regarding Facebook advertising: An exploratory study', The Catalyst 3(1), 1-19. https://doi.org/10.18785/cat.0301.02

Bowden, J.L.-H., 2009, 'The process of customer engagement: A conceptual framework', Journal of Marketing Theory and Practice 17(1), 63-74. https://doi. org/10.2753/MTP1069-6679170105

Brajnik, G. \& Gabrielli, S., 2010, 'A review of online advertising effects on the user experience', International Journal of Human-Computer Interaction 26(10), 971997. https://doi.org/10.1080/10447318.2010.502100

Calder, B., Malthouse, E.C. \& Schaedel, U., 2009, 'An experimental study of the relationship between online engagement and advertising effectiveness', Journal of Interactive Advertising 23, 321-331. https://doi.org/10.1016/j.intmar.2009.07.002

Champoux, V., Durgee, J. \& McGlynn, L., 2012, 'Corporate Facebook pages: When "fans" attack', Journal of Business Strategy 33(2), 22-30. https://doi.org/ 10.1108/02756661211206717

Chang, Y.P. \& Zhu, D.H., 2011, 'Understanding social networking sites adoption in China: A comparison of pre-adoption and post-adoption', Computers in Human Behaviour 27(5), 1840-1848. https://doi.org/10.1016/j.chb.2011.04.006

Chu, S.C., 2011, 'Viral advertising in social media: Participation in Facebook groups and responses among college-aged users', Journal of Interactive Advertising 12(1), 30-43. https://doi.org/10.1080/15252019.2011.10722189

Crespo, Á.H. \& Del Bosque, I.R., 2008, 'The effect of innovativeness on the adoption of B2C e-commerce: A model based on the theory of planned behaviour', Computers in Human Behaviour 24(6), 2830-2847. https://doi.org/10.1016/j.chb.2008.04.008

Curran, K., Graham, S. \& Temple, C., 2011, 'Advertising on Facebook', International Journal of E-Business Development (IJED) 1(1), 26-33.

Cvijikj, P.I. \& Michahelles, F., 2013, 'Online engagement factors on Facebook brand pages', Social Network Analysis and Mining 3(4), 843-861. https://doi. org/10.1007/s13278-013-0098-8

Duffett, R.G., 2015, 'Facebook advertising's influence on intention-to-purchase and purchase amongst Millennials', Internet Research 25(4), 498-526. https://doi. org/10.1108/IntR-01-2014-0020

Facebook, 2011, Best practice guide: Marketing on Facebook, viewed 15 July 2016, from https://www.facebookstudio.com/fbassets/media/856/FacebookBestPractice Guide.pdf

Facebook Investors, 2016, Facebook reports fourth quarter and full year 2015 results, viewed May 2016, from https://investor.fb.com/investor-news/press-releasedetails/2016/Facebook-Reports-Fourth-Quarter-and-Full-Year-2015-Results/ default.aspx

Fishbein, M. \& Ajzen, I., 1975, Belief, attitudes, intention and behaviour. An introduction to theory and research, Addison-Wesley, Boston, MA.

Gaber, H.R. \& Wright, L.T., 2014, 'Fast-food advertising in social media. A case study on Facebook in Egypt', Journal of Business and Retail Management Research 9(1), 52-63.

George, J.F., 2004, 'The theory of planned behaviour and internet purchasing', Internet Research 14(3), 198-212. https://doi.org/10.1108/10662240410542634

Hagger, M.S., Chatzisarantis, N.L.D., Barkoukis, V., Wang, J.C.K., Hein, V., Pihu, M. et al., 2007, 'Cross-cultural generalizability of the theory of planned behaviour among young people in a physical activity context', Journal of Sport and Exercise Psychology 29(1), 1-20. https://doi.org/10.1123/jsep.29.1.2 
Heirman, W. \& Walrave, M., 2012, 'Predicting adolescent perpetration in cyberbullying: An application of the theory of planned behaviour', Psicothema 24(4), 614-620.

Ho, S.S., Liao, Y. \& Rosenthal, S., 2015, 'Applying the theory of planned behaviour and media dependency theory: Predictors of public pro-environmental behavioura intentions in Singapore', Environmental Communications 9(1), 77-99. https://doi. org/10.1080/17524032.2014.932819

Houk, K.M. \& Thornhill, K., 2013, 'Using Facebook page insights data to determine posting best practices in an academic health sciences library', Journal of Web Librarianship 7(4), 372-388. https://doi.org/10.1080/19322909.2013.837346

Hsu, M.H. \& Chiu, C.M., 2004, 'Predicting electronic service continuance with a decomposed theory of planned behaviour', Behaviour \& Information Technology 23(5), 359-373. https://doi.org/10.1080/01449290410001669969

Hubspot, 2012, The 2012 state of inbound marketing, viewed 09 May 2016, from https://cdn2.hubspot.net/hub/53/blog/docs/ebooks/the_2012_state_of inbound_marketing.pdf

Hubspot, 2013, 2013 State of inbound marketing, viewed May 2016, from https:// cdn2.hubspot.net/hub/53/file-30889984pdf/2013_StateofInboundMarketing FullReport.pdf

Jung, J., Shim, S.W., Jin, H.S. \& Khang, H., 2016, 'Factors affecting attitudes and behavioural intention towards social networking advertising: A case of Facebook users in South Korea', International Journal of Advertising 35(2), 248-265. https:// doi.org/10.1080/02650487.2015.1014777

Kabadayi, S. \& Price, K., 2014, 'Consumer - Brand engagement on Facebook: Liking and commenting behaviours', Journal of Research in Interactive Marketing 8(3), 203-223. https://doi.org/10.1108/JRIM-12-2013-0081

Kaiser, H.F., 1974, 'An index of factorial simplicity', Psychometrika 39(1), 31-36. https://doi.org/10.1007/BF02291575

Leng, G.S., Lada, S., Muhammad, M.Z., Ibrahim, A.A.H.A. \& Amboala, T., 2011, 'An exploration of social networking sites (SNS) adoption in Malaysia using technology acceptance model (TAM), theory of planned behaviour (TPB) and intrinsic motivation', Journal of Internet Banking and Commerce 16(2), 1-27.

Liao, C., Chen, J.L. \& Yen, D.C., 2007, 'Theory of planning behaviour (TPB) and customer satisfaction in the continued use of e-service: An integrated model', Computers in Human Behaviour 23(6), 2804-2822. https://doi.org/10.1016/j. chb.2006.05.006

Logan, K., 2014, 'Why isn't everyone doing it? A comparison of antecedents to following brands on Twitter and Facebook', Journal of Interactive Advertising 14(2), 60-72. https://doi.org/10.1080/15252019.2014.935536

Lovett, G., 2011, 'Over 50s drive Facebook growth', Marketing Week, viewed June 2016, from http://www.marketingweek.co.uk/over-50s-drive-facebook-growthstudy-says/3027863.article

Luarn, P., Lin, Y. \& Chiu, Y., 2015, 'Influence of Facebook brand-page posts on online engagement', Online Information Review 39(4), 1-16. https://doi.org/10.1108/ OIR-01-2015-0029

Mahmoud, A.B., 2013, 'Syrian consumers: Beliefs, attitudes and behavioural responses to internet advertising', Business: Theory and Practice/Verslas: Teorija Ir Praktika 14(4), 297-307. https://doi.org/10.3846/btp.2013.31
Maurer, C. \& Wiegmann, R., 2011, 'Effectiveness of advertising on social network sites: A case study on Facebook' Paper presented at the Information and Communication Technologies in Tourism, Innsbruck, 26-28th January, pp. 485-498.

Neal, R.W., 2014, 'Facebook gets older: Demographic report shows 3 million teens left social network in 3 years', viewed May 2016, from http://www.ibtimes.com/ facebook-gets-older-demographic-report-shows-3-million-teens-left-socialnetwork-3-years-1543092

Pallant, J., 2010, SPSS Survival manual, 4th edn., Open University Press, Berkshire.

Pelling, E.L. \& White, K.M., 2009, 'The theory of planned behaviour applied to young people's use of social networking websites', CyberPsychology \& Behaviour 12(6), 755-759. https://doi.org/10.1089/cpb.2009.0109

Potgieter, L.M. \& Naidoo, R., 2017, 'Factors explaining user loyalty in social mediabased brand community', South African Journal of Information Management 19(1), a744. https://doi.org/10.4102/sajim.v19i1.744

Rangeley, R. \& Mollen, A., 2012, 'Engagement: Are we there yet?', viewed June 2016 from http://www.warc.com.ezp01.library.qut.edu.au/Content/ContentViewer aspx?MasterContentRef=30ccf5f3-a85b-4816-8bcb

Renfroe, R., 2015, Blurred lines between paid, earned and owned social media, viewed 15 July 2016, from http://mccom.com/blog/the-blurred-lines-between-paidearned-and-owned-social-media/

Tabachnick, B.G. \& Fidell, L.S., 2007, Using multivariate statistics, 5th edn., Pearson Education, Boston, MA

Truong, Y., 2009, 'An evaluation of the theory of planned behaviour in consume acceptance of online video and television services', The Electronic Journal Information Systems Evaluation 12(2), 177-186.

Tucker, C.E., 2014, 'Social networks, personalized advertising, and privacy controls' Journal of Marketing Research 51(5), 546-562. https://doi.org/10.1509/jmr.10.0355

Viljoen, K.L., Dube, L. \& Muris, T., 2016, 'Facebook versus Twitter: Which one is more credible in a South African context?', South African Journal of Information Management 18(1), a718. https://doi.org/10.4102/sajim.v18i1.718

Wang, M.S., Chen, C.C., Chang, S.C. \& Yang, Y.H., 2007, 'Effects of online shopping attitudes, subjective norms and control beliefs on online shopping intentions: A test of the theory of planned behaviour', International Journal of Management 24(2), 296-302.

Wang, Y. \& Sun, S., 2010, 'Assessing beliefs, attitudes, and behavioural responses toward online advertising in three countries', International Business Review 19 333-344. https://doi.org/10.1016/j.ibusrev.2010.01.004

Williams, L.K., 2017, You want these Facebook engagement rates: Our social media expert roundup, viewed 14 December 2017, from https://www.agorapulse.com

World Wide Worx, 2016, Instagram, Facebook make waves in SA, viewed 08 August 2016, from http://www.worldwideworx.com/socialsa2016/

Yanovitzky, I., Stewart, L.P. \& Lederman, L.C., 2006, 'Social distance, perceived drinking by peers, and alcohol use by college students', Health Communication 19(1), 1-10. https://doi.org/10.1207/s15327027hc1901_1

Yap, S.F.C. \& Lee, C.K.C., 2014, 'Leveraging the power of online social networks: A contingency approach', Marketing Intelligence \& Planning 32(3), 345-374. https://doi.org/10.1108/MIP-03-2013-0048 